\title{
Estudo da mudança na interface metal-metal para metal - PEEK \\ (Poli-eter-eter-cetona) em componentes de transmissões \\ mecânicas manuais visando o aumento da resistência ao desgaste
}

\author{
Luigi Marson e Marcelo Massarani \\ CEA - USP \\ E-mails: eng_luigi@hotmail.com, massarani@me.com
}

\section{RESUMO}

Um grande desafio foi colocado para a indústria automotiva, projetar transmissões eficientes que sejam capazes de rodar com baixos volumes de óleo sem afetar a robustez do projeto, tendo em vista que esta redução pode ter efeitos colaterais nocivos à vida da transmissão, como por exemplo aumento da incidência de desgaste. $\mathrm{O}$ tema desenvolvido neste trabalho vem ao encontro deste desafio propondo uma alternativa quanto ao aumento da resistência ao desgaste, introduzindo e detalhando questões de projeto de uma outra tendência crescente na industria automobilística, o uso de polímeros de alto desempenho na substituição dos aços convencionais. A idéia proposta neste trabalho trata especificamente do aumento da resistência ao desgaste que a mudança na interface metal-metal para metal-PEEK (poli-etereter-cetona) proporciona, buscando embasamento científico para tal em pesquisas recentes e ainda em desenvolvimento sobre a interação metal-PEEK e nas hipóteses que vêm sendo discutidas nos fóruns científicos, como por exemplo, o fenômeno da transferência de filme de PEEK, a fim de mostrar como a alteração tribológica de interfaces metal-metal por metalPEEK podem aumentar a resistência ao desgaste (que neste trabalho foi cerca de cinco vezes).

\section{INTRODUÇÃO}

Há no mercado de transmissões mecânicas, assim como no mercado de componentes ligados ao trem de força, uma tendência de se agregar valor a produtos com alta eficiência mecânica, devido também, em especial se tratando de Brasil, das metas do Inovar-Auto. No caso das transmissões, a perda energética ou de eficiência está ligada a 5 subsistemas e para todos eles as perdas se relacionam ao atrito. $\mathrm{O}$ atrito em cada subsistema é detalhado a seguir: 
1. Atrito gerado pelo contato entre eixos e vedadores;

2. Atrito nos dentados dos pares de engrenagens contra postas responsáveis pelas diferentes relações de transmissão de torque de cada marcha;

3. Atrito nos anéis e conjuntos sincronizadores, componentes responsáveis pela sincronização de rotação entre eixo e engrenagens, fenômeno este que permite a troca de marcha;

4. Atrito do óleo da transmissão com os componentes internos;

5. Atrito entre os elementos rolantes do rolamento e as pistas internas e externas.

Seguindo esta lógica, desenvolvimentos para os cinco subsistemas estão em plena atividade com a finalidade de se ter componentes que dissipem menos potência, trabalhando com coeficientes de atrito reduzidos.

Algo que se inclui dentro desse desenvolvimento e já é uma realidade no mercado é a redução do volume de óleo com o qual uma transmissão pode funcionar. Assim sendo, um grande desafio foi colocado para a indústria, projetar componentes dentro dos cinco subsistemas citados que ajudem a transmissão a ser mais eficiente e desenvolver transmissões que sejam capazes de rodar com baixos níveis de óleo sem afetar a robustez e confiabilidade do projeto. Este tema vem de encontro deste desafio e mostra como a alteração tribológica de interfaces metal-metal por metal-PEEK pode aumentar a resistência ao desgaste e ser uma importante ferramenta no desenvolvimento desta nova geração de transmissões mecânicas.

Durante a elaboração deste trabalho, pôde-se discutir a utilização do PEEK como interface para componentes metálicos a fim de se reduzir a taxa de desgaste em regiões e meios propícios ao aparecimento deste modo de falha. Neste estudo foi utilizado o material VICTREX ${ }^{\circledR} 150 C A 30$ e foi mostrado que a criação de um componente adjacente à interface onde o desgaste se manifestava pode minimizar os efeitos deste fenômeno na ordem de cinco vezes quando comparado com a interface metal-metal.

\section{ESTUDO DE ALTERAÇÃO DE INTERFACE}

\subsection{FENÔMENO DO DESGASTE}

O fenômeno do desgaste estudado neste trabalho é conhecido pela a literatura como Fretting. Segundo Stachowiak e Batchelor (1993), este fenômeno de desgaste ocorre sempre quando movimentos de escorregamento alternados de baixa amplitude são sustentados por longos períodos ou por um grande número de ciclos.

No caso deste estudo, as cargas que excitam o movimento alternado são as cargas axiais oriundas dos engrenamentos que constituem as relações de marchas.

Pela característica inerente à transmissão de torque de um par de engrenagens contrapostas, a carga axial exercida nos componentes em contato com este par de engrenagens é cíclica e se aproxima de um carregamento pulsante, com razão de carga próxima de 1, estando sua freqüência ligada com sua relação de transmissão: quanto maior a rotação de uma das engrenagens do par, maior a freqüência de transferência de carga axial.

Caracterizada a origem do carregamento alternado, agora se caracterizará a baixa amplitude do movimento de escorregamento entre as superfícies em contato aqui 
estudadas. As conexões ranhuradas ou estriadas geralmente utilizadas em cubos sincronizadores dão ao componente este grau de liberdade de baixa amplitude.

Segundo Stachowiak e Batchelor (1993), até mesmo ajustes com interferência permitem um movimento de escorregamento na ordem de grandeza de $1 \mu \mathrm{m}$ que já podem gerar o fenômeno de Fretting.

Portanto, define-se a partir daqui as condições responsáveis pelo desenvolvimento do fenômeno do desgaste em questão. Em suma, como descreve Stachowiak e Batchelor (1993), é um fenômeno relacionado a grandes números de ciclos e a grandes tempos de exposição em condições de carregamentos alternados, tornando-se mais afetado com a maior freqüência destes carregamentos, ou seja, com maiores rotações nas árvores de transmissão.

A região do desgaste a ser estudado é a região que reage a estes carregamentos. Infere-se a partir da figura abaixo (Figura 1) que a região que reage às forças oriundas do engrenamento é a região de encosto entre o cubo sincronizador, mostrado na cor amarela, e a árvore de transmissão, mostrada em azul.

Ainda, segundo Hutchings (1992), um dos locais mais comuns para ocorrência do fenômeno do fretting é em cubos prensados em eixos rotacionais, entretanto, sabemos que para ocorrência do fretting, oscilações na ordem de grandeza de até $100 \mu \mathrm{m}$ são plausíveis.

Figura 1 : Detalhamento de um sistema sincronizador e seus respectivos componentes.

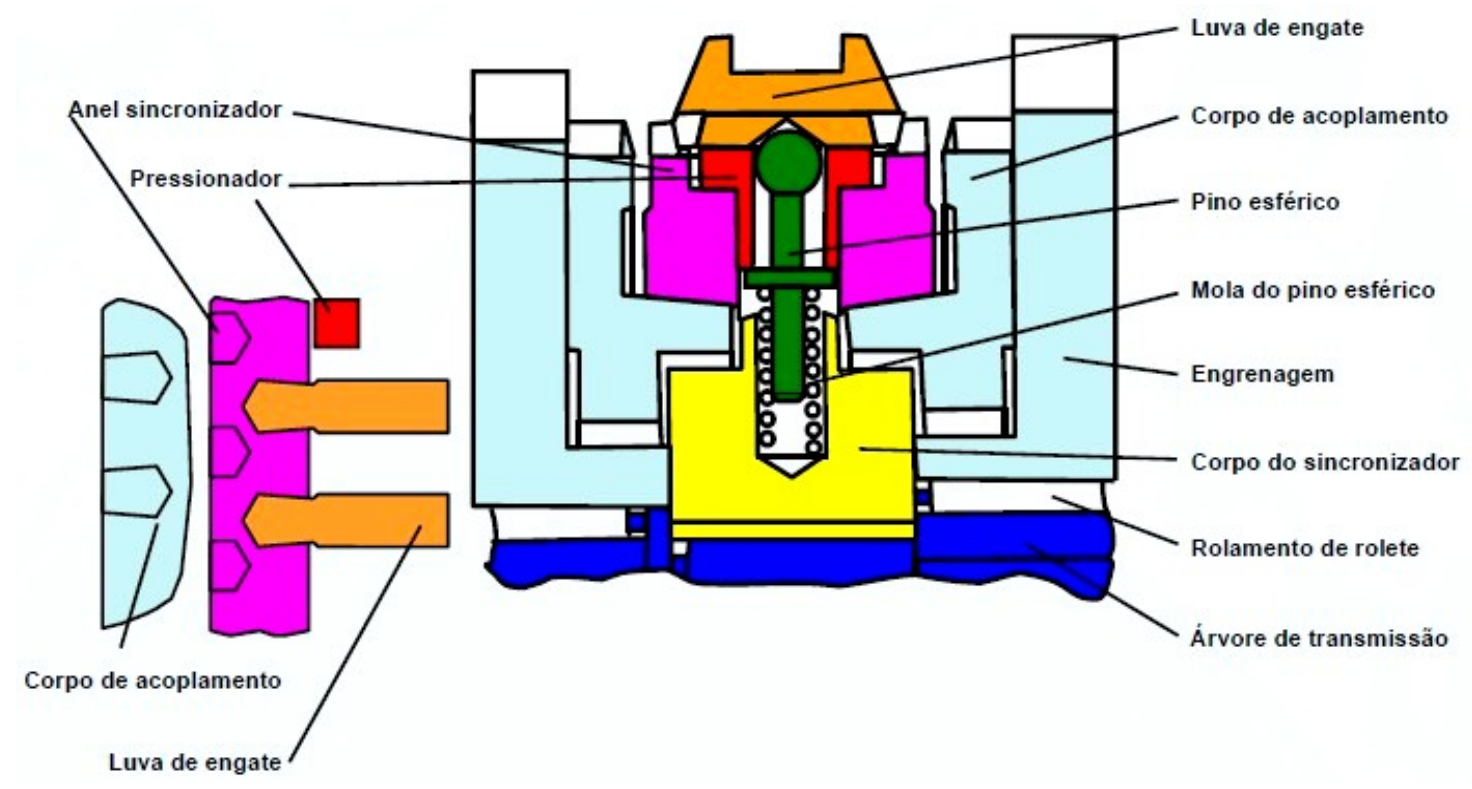

Fonte: Curso Modular em Transmissões SAE (2013).

Portanto, a partir deste tópico são esclarecidas as condições que geram o fenômeno do desgaste a ser estudado, assim como as regiões onde ocorre este desgaste específico e a ordem de grandeza de seus movimentos oscilatórios, caracterizado de acordo com a literatura aqui apresentada e pelos indícios físicos, como a formação do óxido vermelho na interface desgastada. 


\subsection{APARÊNCIA DO DESGASTE}

Segundo Bayer (2004), o desgaste possui três níveis de classificação. O primeiro deles é quanto à aparência das marcas geradas por tal desgaste que será apresentado nesta seção. $\mathrm{O}$ segundo é quanto ao mecanismo físico que remove o material dos componentes em contato. O terceiro nível se dá quanto ao meio em que o desgaste ocorre. Segundo o mesmo autor, os níveis de classificação são importantes porque auxiliam engenheiros e projetistas a relacionarem a aparência das marcas do desgaste com o mecanismo físico que o gera, remetendo-os por sua vez ao ambiente ou meio que promove seu desenvolvimento, referenciando-se, dessa maneira, com modelos já existentes de detecção, previsão e controle deste desgaste.

Figura 2 : Análise metalúrgica da árvore de transmissão apresentando desgaste. Região de encosto com o cubo sincronizador.

Fonte: Autor.

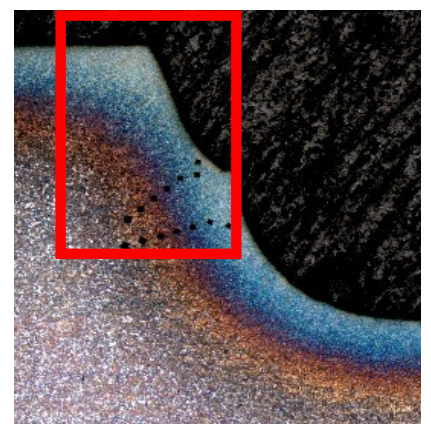

$\mathrm{Na}$ imagem acima, na região destacada pelo quadrado vermelho, é possível observar que material foi removido da região do encosto entre a árvore de transmissão e o cubo sincronizador, adequando-se ao conceito de desgaste de Stoeterau (2004) que diz que, o desgaste é uma mudança cumulativa e indesejável em dimensões motivada pela remoção gradual de partículas discretas de superfícies em contato e com movimento relativo devido, predominantemente, a ações mecânicas.

\subsection{MECANISMO FÍSICO DO DESGASTE}

Antes de iniciar a discussão sobre o mecanismo do desgaste, é importante frisar que o termo Fretting se refere apenas à natureza do movimento, sem incluir o mecanismo de desgaste apresentado que pode ser dividido em Fretting Wear (FW), onde pequenos deslocamentos estão relacionados a vibrações externas, Fretting Fatigue (FF), relacionado a deformações cíclicas, e Fretting Corrosion (FC), relacionado por sua vez a reações químicas que ocorrem no processo tribológico também envolvendo escorregamento de pequenas amplitudes.

Segundo Kpasa et all (2005), Fretting é um fenômeno complexo relacionado à interação de dois corpos com movimento relativo de escorregamento separados por um terceiro corpo onde há vários processos superficiais e subsuperficiais envolvidos e para cada um dos tipos de desgaste promovidos pelo fretting há alguns desses fenômenos envolvidos.

No caso deste estudo, não há formação de trincas na superfície desgastada, características do mecanismo de Fretting Fatigue, somente remoção de material e indícios de formação de uma camada de óxido na região do desgaste (FW e FC). 
Partindo dos indícios apresentados nos testes de dinamômetro de bancada e tendo como base o conceito para desgaste induzido por Fretting (WIF Wear induced by fretting) de Kpasa et all (2005), que descreve o processo de dano gerado pelos mecanismos de desgaste do fretting FW e FC, podemos correlacionar o fenômeno do estudo com a descrição a seguir do WIF segundo Kpasa et all (2005):

- Remoção de camadas superficiais de óxido e o aumento do contato metal-metal;

- Formação de uma nova microestrutura chamada estrutura tribologicamente transformada (TTS). A TTS é uma estrutura nano cristalina que se torna frágil e se quebra com o deslocamento das superfícies em contato. O destacamento destas partículas se dá predominantemente por mecanismos de abrasão e adesão;

- Os detritos metálicos são então aprisionados, esmagados e oxidados na interface das superfícies em contato, induzindo a formação de uma camada de detritos (vermelha, no caso de aços). Neste caso havia formação de camada oxidada vermelha após os testes em dinamômetro.

- O estabelecimento de um terceiro corpo formado por esses detritos oxidados dependem da possibilidade deles serem removidos da região do contato ou não, possibilidade relacionada ao formato dos detritos e às excitações do ambiente. Se os detritos da camada oxidada não saírem da região de contato, a degradação de material pode ser atenuada devido à acomodação que esta camada promove diminuindo a velocidade relativa entre as superfícies em contato. Para este caso em específico, a remoção de material era contínua, sem acomodação da TTS.

Figura 3 : Processo de formação da camada de óxido no desgaste induzido por Fretting.

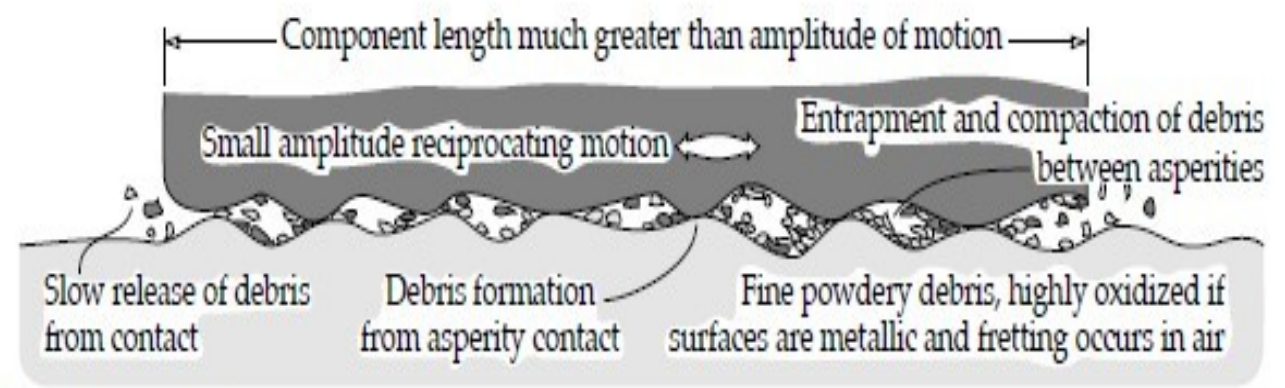

Initial stages of fretting

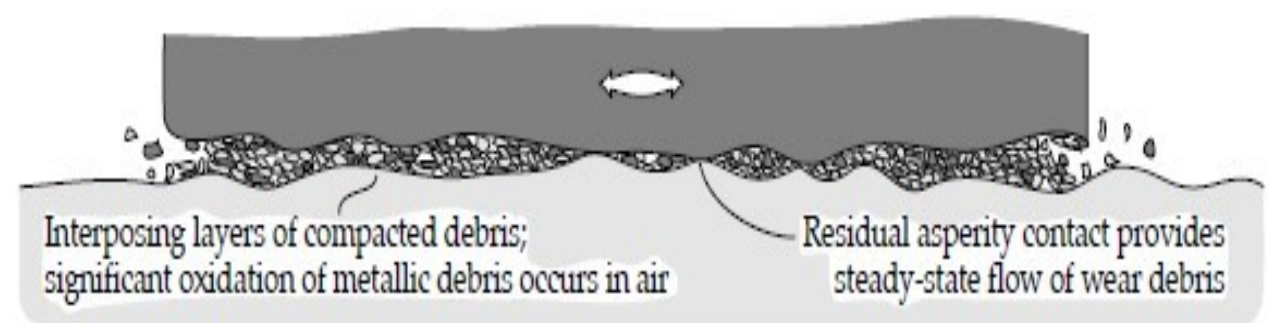

Fonte: Stachowiak e Batchelor (1993). 
Figura 4 : Formação da camada de óxido no desgaste induzido por Fretting em estria de eixo, região de encosto com cubo sincronizador.

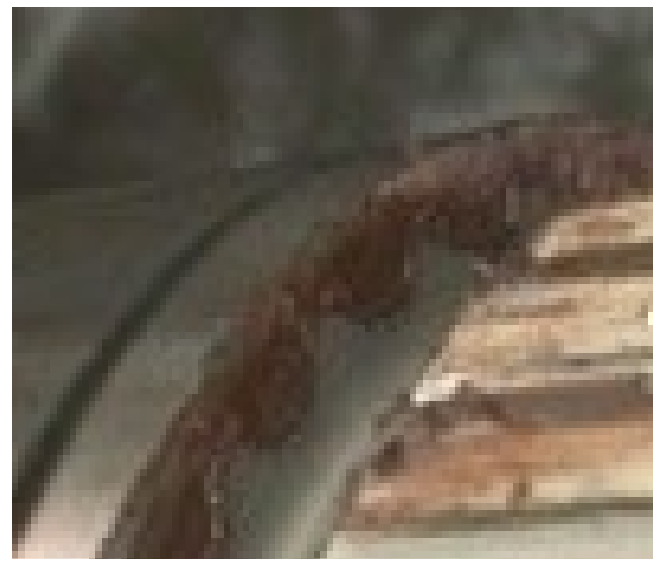

Fonte: Autor.

\section{4 - ALTERAÇÃO DE INTERFACE - PASSO A PASSO}

\subsection{1 - Análise Da Configuração Construtiva Original}

A configuração construtiva original, alvo deste estudo, se caracteriza pelo encosto do cubo sincronizador na árvore de transmissão. Em acordo com a figura abaixo.

Figura 5 : Configuração construtiva original, interface metal-metal

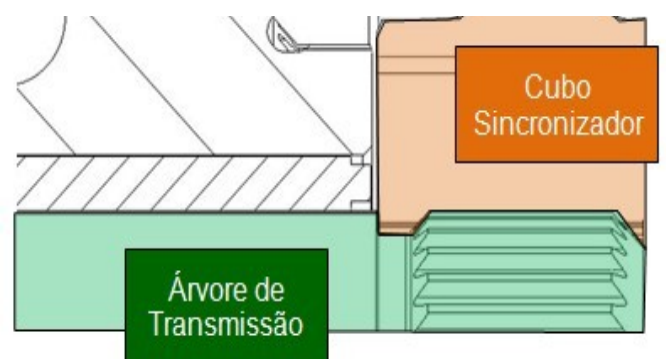

Fonte: Autor.

\subsection{2 - Modificação Nos Componentes}

Para se alterar a interface da região desgastada, alterando assim a interação tribológica do sistema, planejou-se a criação de um componente adjacente ao encosto do cubo com a árvore de transmissão. Assim foi projetado uma arruela de encosto. Para permitir a montagem desta arruela e conservar as folgas axiais de engrenagens e sistemas de sincronização foi necessária uma adaptação no cubo sincronizador, um rasgo foi usinado no cubo. 


\subsection{3 - Projeto Do Componente Em PEEK}

A arruela de PEEK foi projetada também visando a resistência aos esforços que o componente teria que resistir. Como a região onde o desgaste ocorre é exatamente a mesma onde as forças axiais oriundas do engrenamento reagem, a arruela tem obrigatoriamente que resistir a estes mesmos esforços. Através de análise de elementos finitos, foi definida uma espessura mínima que a arruela teria que ter sem comprometer a estrutura do cubo, pois quanto maior a espessura da arruela, maior o rasgo que o cubo teria que ter para permitir a montagem da mesma. Em outras palavras, pode-se dizer que quanto mais resistente a arruela se torna, mais frágil o cubo fica, caracterizando assim um compromisso entre espessura da arruela e perda de resistência do cubo.

A imagem abaixo mostra a configuração construtiva já com a montagem da arruela de PEEK:

Figura 6 : Configuração construtiva da arruela de PEEK montada.

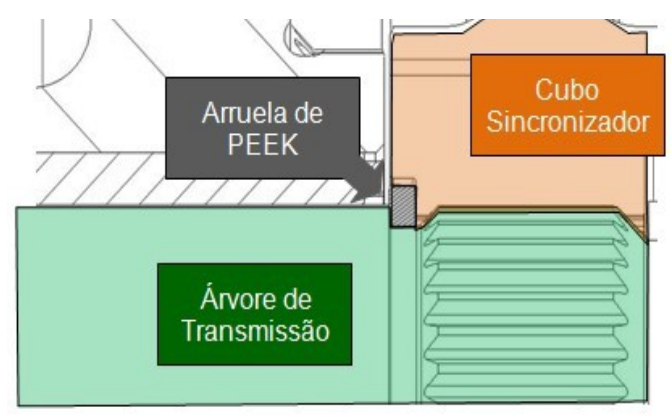

Fonte: Autor.

Figura 7: Arruela de PEEK. Abertura na seção transversal para permitir montagem.

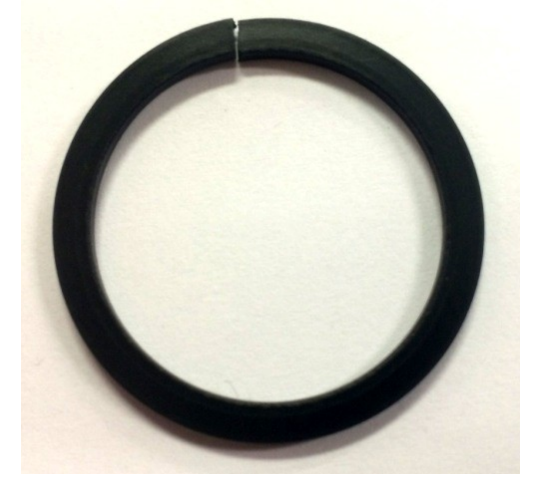

Fonte: Autor.

A aplicação deste material em arruelas de encosto já é algo que começa a ser amplamente difundido pelos fabricantes do PEEK para aplicações automotivas. 
Figura 8: Arruelas de PEEK já fornecidas pela VICTREX.

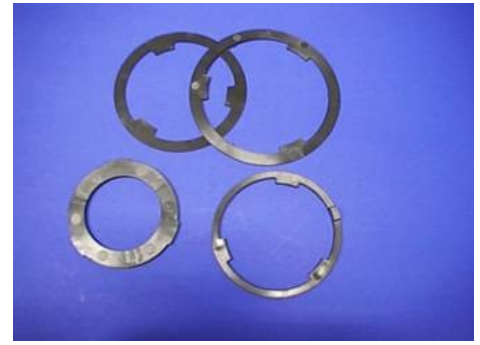

Fonte: VICTREX PLC.

\subsection{RESULTADOS COMPARATIVOS}

Até a presente seção, já foi apresentado de que forma o fenômeno ocorre, sua aparência, região foco do estudo e etc., assim como foi explanado os fatores de influência deste fenômeno.

Na seção anterior foi mostrado como o projeto foi alterado para mudar a interface metalmetal para metal-PEEK e como o componente adjacente à região do desgaste foi desenhado com a finalidade de se ter a menor alteração possível de projeto e para resistir aos esforços oriundos das forças axiais dos engrenamentos.

Nesta seção serão mostrados os resultados obtidos com esta alteração de projeto nos testes de dinamômetro de bancada onde um torque mecânico é aplicado. Após aplicação deste torque mecânico, um motor elétrico rotaciona o sistema para, desta forma, simular o funcionamento de um veículo.

Gráfico 1 : Comparativo entre desgaste de interface metal-metal e metal-PEEK em 100 horas de teste em bancada.

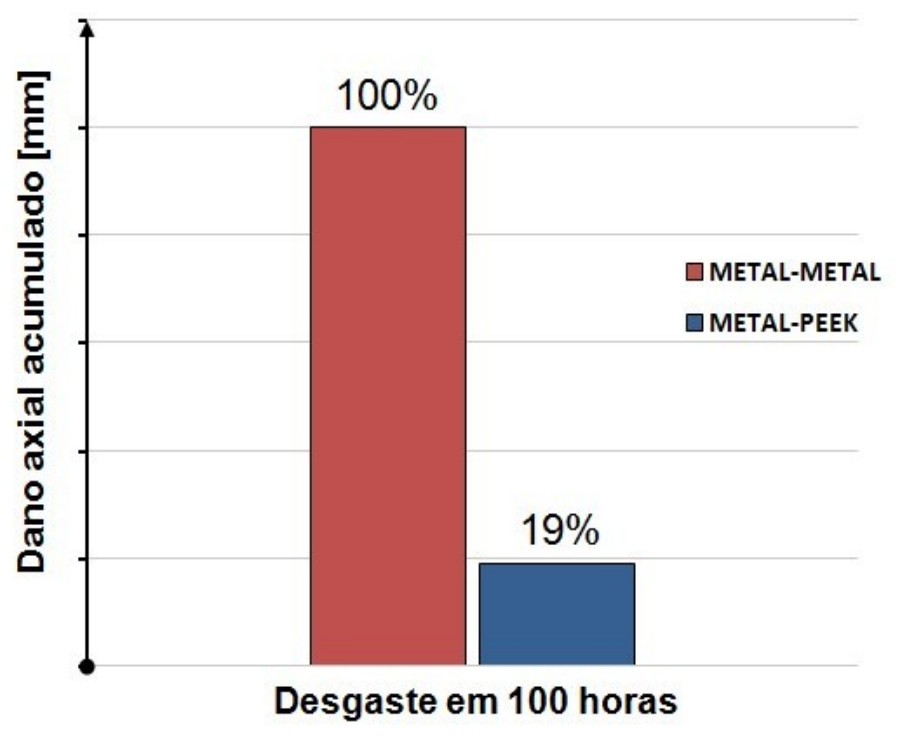

Fonte: Autor. 
Infere-se a partir do gráfico acima que ao considerar a taxa de desgaste para a interface metal-metal como $100 \%$, para a interface metal-PEEK houve uma queda na taxa de desgaste de cerca de 5 vezes.

Os resultados apresentados no gráfico representam a média dos desgastes de cinco amostras testadas para cada configuração. O desgaste é medido na forma de dano axial, ou seja, é mensurado o quanto axialmente o material foi removido da árvore de transmissão. Veja figura abaixo.

Figura 9 : Medição do dano axial causado pelo desgaste na árvore de transmissão.

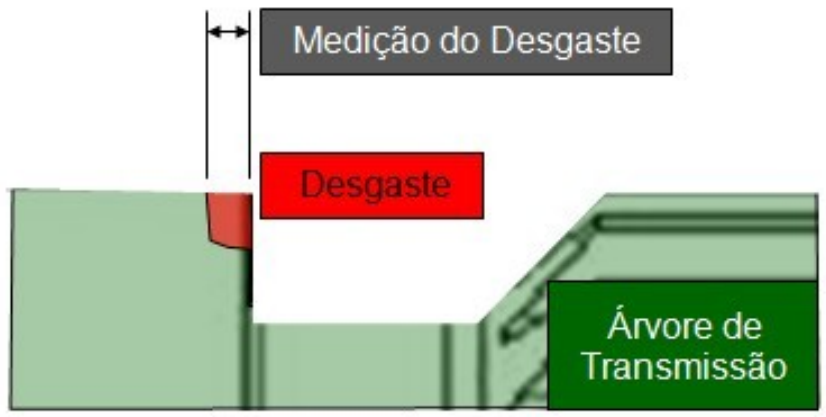

Fonte: Autor.

\section{6 - HIPÓTESES PARA A REDUÇÃO DA TAXA DE DESGASTE}

\subsection{1 - Formação De Filme De Transferência}

O mecanismo de desgaste induzido por fretting se dá, como citado, pela formação de uma camada de detritos oriundos de outros mecanismos de desgaste como, por exemplo, a abrasão e a adesão, que oxidados, formam então uma camada de material que vai sendo renovado conforme os detritos vão sendo expelidos da região do desgaste. Portanto, é um fenômeno tribológico. Segundo Briscoe e Sinha (2005), com a interface alterada para metal-polímero, os detritos oriundos assumem formas cilíndricas como quando se apaga uma marca de lápis com uma borracha, nota-se estruturas cilíndricas formadas devido à interação entre as duas superfícies. Estes corpos cilíndricos serão constituintes da estrutura, ou filme de transferência, formado entre as duas superfícies em contato e ajudarão a reduzir os movimentos de escorregamento entre as duas superfícies, acomodando os possíveis movimentos de rolagem e reduzindo assim a taxa de desgaste.

Ainda segundo Stachowiak e Batchelor (1993), os polímeros são mais eficientes em termos de desgaste quando em contato com superfícies metálicas do que quando em contato com outra superfície polimérica devido ao filme de transferência que é formado quando o polímero é exposto a movimentos de escorregamento contra superfícies duras.

A formação de filme de transferência é mostrada no trabalho de Koike et al (2011), que construiu um experimento aplicando cargas radiais e rotação a um rolamento feito de PEEK em suas pistas internas e externas e com seus elementos rolantes, esferas de alumínio, e verificou a ocorrência do filme de transferência nas esferas após o teste. 
Figura 10: Esferas de alumínio pertencentes ao experimento de Koike et al (2011), com adesão de PEEK em seu perímetro.
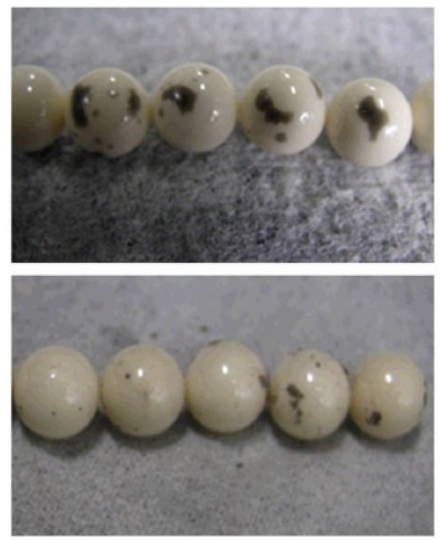

Fonte: Koike et al (2011).

Também é evidenciado nos experimentos de Chen et al (2011), que construiu uma bancada para avaliar desgaste de corpos submetidos a movimentos de escorregamento, a presença de filme de transferência.

Em seus experimentos foram estudados diversas composições de polímeros, sempre usando as resinas PEEK, PEI e PES e foi constatado que somente os polímeros que utilizavam PEEK em sua composição apresentaram formação de filme de transferência significativo, em acordo com a figura abaixo.

Figura 11: Formação de filme de transferência nas seguintes composições de material (A) PEEK 100\%, (B) PEEK 70\%, PEI 25\%, PES 5\%, (C) PEEK 65\%, PEI 30\%, PES 5\%, (D) PEEK 60\%, PEI 30\%, PES 5\%.

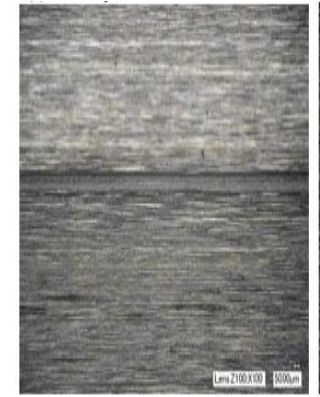

(a)

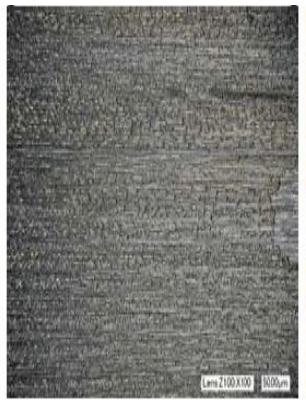

(b)

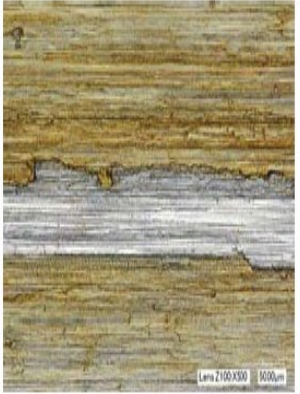

(c)

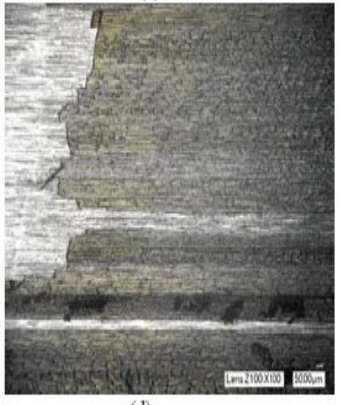

(d)

Fonte: Chen et al (2011).

Também há neste estudo indícios de formação de filme de transferência nas regiões dos componentes metálicos de interface com a arruela de PEEK, caracterizados pela adesão do PEEK, material de cor preta na superfície metálica. 
Figura 12: Indícios de formação de filme de transferência no cubo sincronizador, região de encosto com a arruela de PEEK, indicada pelas setas vermelhas.

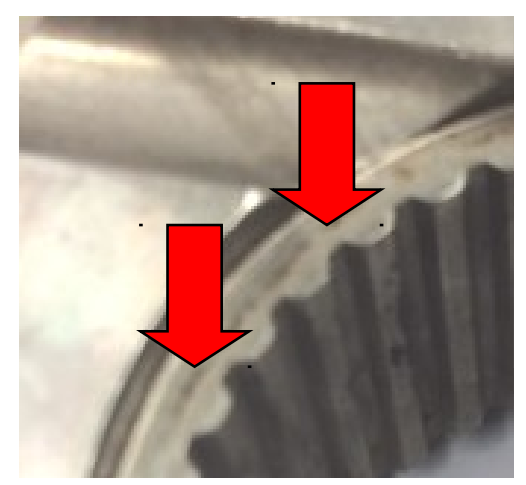

Fonte: Autor.

Caracterizado o fenômeno tribológico inerente ao contato metal-polímero e, em específico, ao contato metal-PEEK, infere-se que a transferência de filme é o fenômeno ao qual mais se atribui a diminuição da taxa de desgaste para diversos tipos de movimentos relativos. Na figura abaixo, Bayer (2004) mostra o efeito da transferência de filme para desgaste por abrasão que também contribui para o processo de fretting, assim como mostra uma diminuição na taxa de desgaste próxima a 5 vezes com a formação do filme de polímero, números próximos ao mostrado neste estudo.

Figura 13: Queda na taxa de desgaste por abrasão causado pela transferência de filme polimérico.

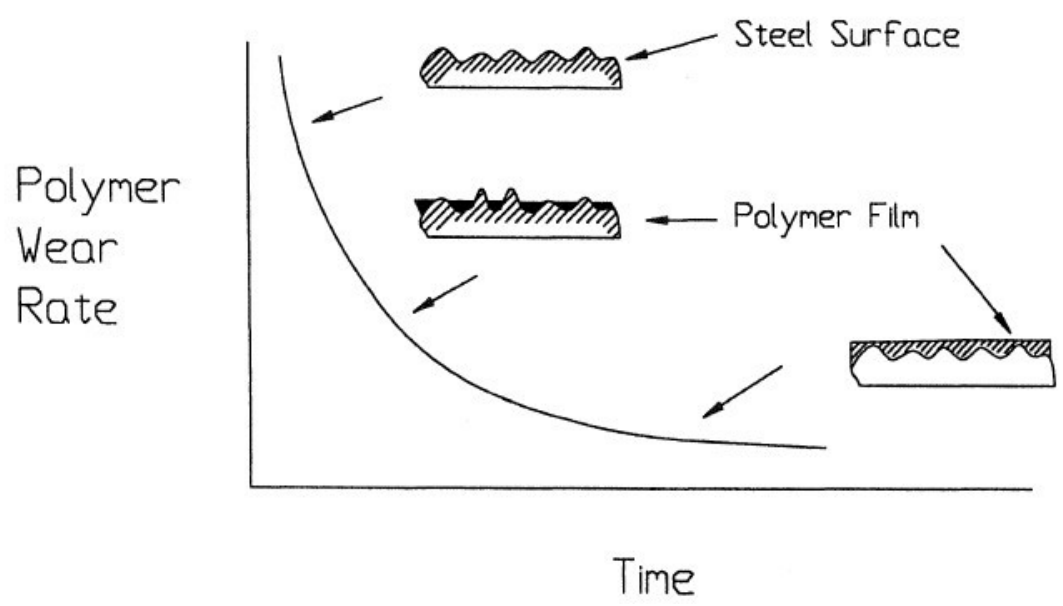

Fonte: Bayer (2004).

\subsection{2 - Distribuição De Cargas (Cushion Effect)}

Outro aspecto de influência no aumento da resistência ao desgaste em interfaces metal-POLÍMERO é a acomodação que a menor rigidez dos polímeros garante. Uma distribuição de carga mais homogênea ao longo da interface estudada garante menores oscilações de movimento e menores tensões de contato entre as asperezas das superfícies, fazendo com que se diminua a incidência de desgaste nesta interface. 
O gráfico abaixo registra a análise das duas interfaces da arruela de PEEK e duas interfaces de uma mesma arruela de metal via elementos finitos, garantindo uma análise comparativa justa, pois a única variável neste método foi o material da arruela, garantido assim a avaliação apenas da mudança de rigidez do material. Verifica-se que para uma mesma configuração de projeto, o PEEK garantiu uma melhor distribuição de pressão ao longo da interface desgastada.

Gráfico 3: Distribuição de carga ao longo da interface metal-PEEK comparado com interface metal-metal. Interface 1.

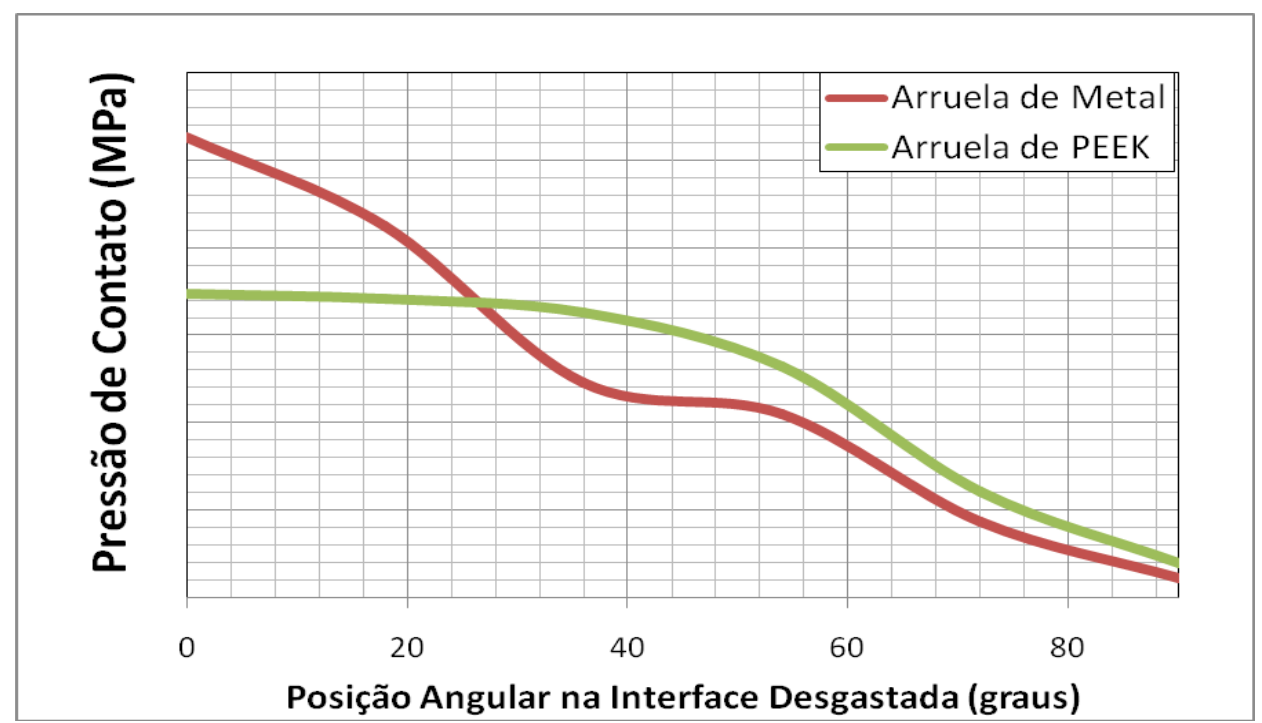

Fonte: Autor.

Gráfico 4: Distribuição de carga ao longo da interface metal-PEEK comparado com interface metal-metal. Interface 2.

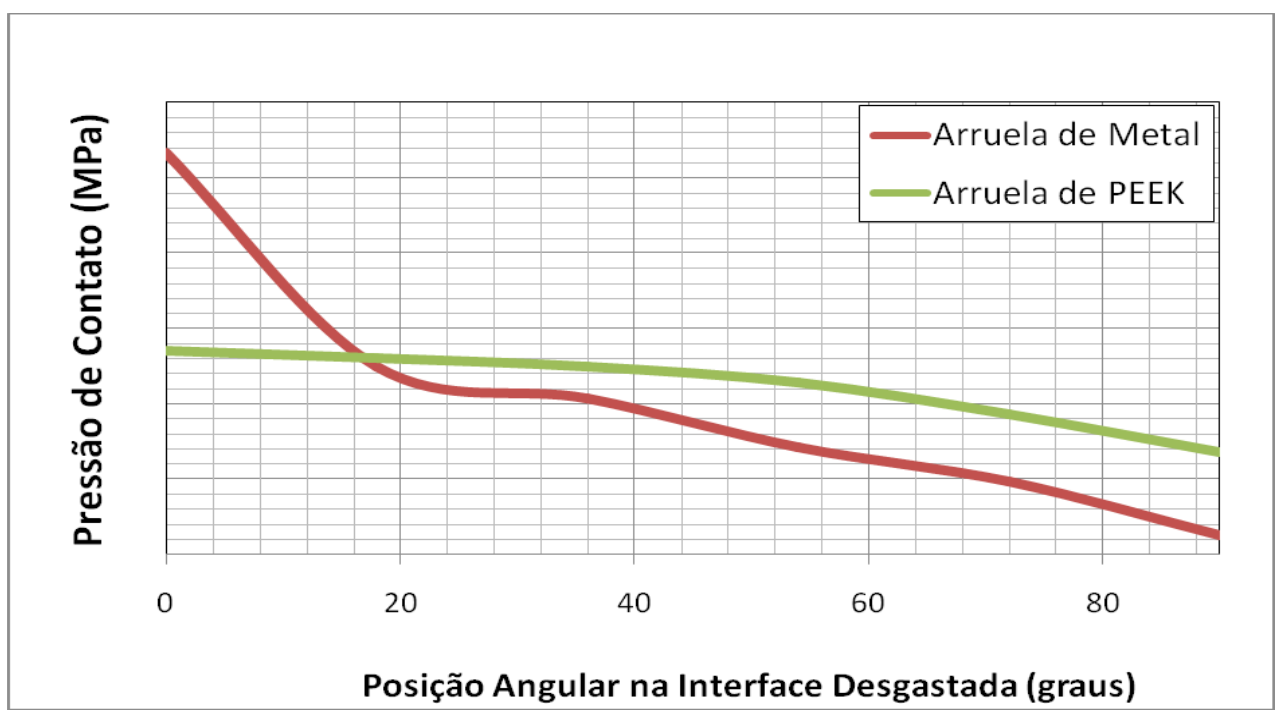

Fonte: Autor. 


\section{CONCLUSÃO}

Conclui-se que apesar de não se ter utilizado recurso de microscopia eletrônica de varredura para se comprovar o fenômeno de transferência de filme, buscou-se embasamento prático e literário para o levantamento da hipótese para o estudo analisado neste trabalho. Conclui-se também que a ferramenta de alteração de interface metal-metal para metal-PEEK se mostrou eficaz e que a aplicação do VICTREX ${ }^{\circledR}$ PEEK 150CA30 em componentes de transmissão mecânica através da criação de componentes adjacentes como arruelas de encosto tem grande potencial, tanto pelas características tribológicas do material como pelas excelentes propriedades mecânicas que apresenta, chegando a patamares superiores a ligas de alumínio fundidas em baixa pressão. Também vale ressaltar o excelente comportamento em relação à fluência e ao envelhecimento, tornando o material ainda mais propício para aplicação sugerida neste trabalho.

Outro ponto positivo deste trabalho a ser destacado nesta conclusão é o desenvolvimento deste componente em PEEK atrelado aos resultados obtidos que quebraram paradigmas relacionados aos polímeros aplicados em transmissões mecânicas, paradigmas que outrora foram obstáculos para outros desenvolvimentos e que agora quebrados, possibilitarão e incentivarão novos desenvolvimentos de componentes poliméricos.

\section{REFERÊNCIAS}

[4] BAYER, R.G. Mechanical Wear Fundamentals and Testing. 2nd ed. Revised and Expanded. New York: Marcel Dekker, Inc, 2004. 396 p.

[8] BRISCOE, B. J; SINHA, S.K. Tribology of Polymeric Solids and Their Composites. Wear: Materials, Mechanisms and Practice. Tribology in Practice Series. West Sussex: Wiley Editorial, 2005. 453 p.

[10] CHEN, J; GUO, Q; ZHANG, S; WANG, X; SHAO, X. Research on Friction and Wear Behaviors of PEEKSelf-lubrication of PEEK/PEI/PES Plastic Alloys under Sliding Contact Condition. SciVerse ScienceDirect, Shanghai, p. 285 - 291, 2012.

[2] HUTCHINGS, I. M. Tribology: friction and wear of engineering materials. London: Eadward Arnold, 1992. 273 p.

[9] KOIKE, H; KIDA, K; SANTOS, E. C; ROSWADOWSKA, J; KASHINA, Y; KANEMASU, K. Self-lubrication of PEEK polymer bearings in rolling

[6] KPASA, P; FOUVRY, S; VINCENT, L. Basic Principles of Fretting. Wear: Materials, Mechanisms and Practice. Tribology in Practice Series. West Sussex: Wiley Editorial, 2005. $453 \mathrm{p}$.

[3] PERESTRELO, L. Curso modular SAE em transmissões. São Paulo: SAE-BRASIL, 2013. $427 \mathrm{p}$.

[1] STACHOWIAK, G.W; BATCHELOR, A.W. Engineering Tribology. Third Edition. Oxford: Elsevier Inc, 2005. 801 p. 
[5] STOETERAU, R. L. Tribologia. Santa Catarina: Universidade Federal de Santa Catarina, Centro Tecnológico, Departamento de Engenharia Mecânica, 2004. 172 p. Apostila do curso EMC 5315 